\title{
O ESPAÇO DA QUÍMICA NOS CENTROS E MUSEUS DE CIÊNCIAS BRASILEIROS
}

\author{
Ana C. da S. Steola* e Ana C. Kasseboehmer \\ Departamento de Físico-Química, Instituto de Química de São Carlos, Universidade de São Paulo, Campus São Carlos,
} Av. Trabalhador São-Carlense, 400, 13566-590 São Carlos - SP, Brasil

Recebido em 30/10/2017; aceito em 03/05/2018; publicado na web em 07/06/2018

\begin{abstract}
THE SPACE OF CHEMISTRY IN THE BRAZILIAN SCIENCE CENTERS AND MUSEUMS. There are several consequences of the negative or poor perception that society tends to maintain with Chemistry like the lack of interest of students in considering Chemistry as a career or the university dropout rates. Given the importance of museums and science centers to contribute to scientific education and arouse people's interest in science, this article presents a research carried out with Brazilian science centers and museums to appraise the space of Chemistry in non-formal places of Education. The results obtained are similar to some international data showing the amount of chemistry-related content in museums is insufficient, not exceeding the $40 \%$ rate. Most of the activities are aimed at supporting formal education by offering courses for teachers and students through the use of laboratories or conducting experiments when there is available monitoring. Chemistry can be considered in the development of science museums exhibitions and, with the guidance of scientists, it can be shown and discussed without creating distorted visions, sensationalism or conceptual misconceptions.
\end{abstract}

Keywords: science museum; chemistry dissemination; chemistry popularization.

\section{INTRODUÇÃO}

Diversas são as consequências da relação que a sociedade tende a manter com a Química, geralmente associando-a a fatos negativos como poluição, envenenamento, etc. ${ }^{1,2}$ Em primeiro lugar, a falta de divulgação sobre a carreira de Química, seus atrativos e possibilidades profissionais, leva poucos estudantes de ensino médio a optarem pelo curso de Química no vestibular. Mais acentuadamente nas instituições consolidadas que oferecem um rol maior de cursos, a procura por essa carreira científica tanto em cursos de bacharelado quanto de licenciatura é baixa, chegando a $1,7^{3}$ e não excedendo 11 candidatos por vaga, ${ }^{4}$ números bastante diferentes quando comparados com Engenharia Civil (33 candidatos por vaga) ${ }^{4}$ ou Medicina (221 candidatos por vaga). ${ }^{4}$

Daqueles que ingressam nos cursos de Química, a falta de conhecimento sobre essa área científica, associada a deficiências formativas na educação básica, são as principais explicações para a evasão universitária. ${ }^{5}$ Enquanto a baixa procura pelos cursos de Química no vestibular leva à baixa competitividade entre os candidatos, menor seletividade $\mathrm{e}$ prováveis prejuízos na qualidade do ensino superior, a evasão diminui a quantidade de profissionais disponibilizados no mercado.

Outra consequência de não se superar a associação da Química a fatos e eventos negativos é a perpetuação das concepções equivocadas sobre ciência e cientistas, denominadas ${ }^{6}$ de visões distorcidas, que se difundem entre estudantes de todos os níveis de ensino e entre a sociedade. Como exemplo dessas visões tem-se a concepção de que o conhecimento científico é fruto de uma descoberta inesperada - ideia bastante divulgada pela mídia, especialmente na literatura das histórias em quadrinhos - ou a visão de cientistas como pessoas "acima do bem e do mal" " que não se deixam influenciar pelas relações entre ciência, tecnologia e sociedade. Se a carreira científica continuar a ser reconhecida como exclusiva de pessoas extremamente inteligentes ou com "dom" para a área, poucos estudantes se identificarão com essa profissão e a baixa procura nas universidades continuará a propagar-se.

\footnotetext{
*e-mail: krollsteola@gmail.com
}

Diante desse quadro, ações em diferentes âmbitos vêm sendo tomadas para estimular o desenvolvimento de uma visão mais madura e positiva das ciências pela população. Para exemplificar, em entrevista à Agência Fapesp, Nicole Jeanne Moreau, presidente da União Internacional da Química Pura e Aplicada (IUPAC, na sigla em inglês), menciona que foi prioridade das atividades destinadas à comemoração do Ano Internacional da Química reverter a imagem que a população tem dessa área do conhecimento:

\begin{abstract}
Para o público a química significa poluição, sujeira, perigo, em oposição a tudo o que é limpo e saudável. Mas as pessoas esquecem que a medicina, as drogas, a energia vem da química. Ninguém quer saber disso. E nós não sabemos exatamente como explicar ao público. Acho apenas que não devemos ficar na defensiva, tentando negar as acusações contra a química. Devemos apenas mostrar o que ela realmente é. ${ }^{7}$
\end{abstract}

Também podem ser apontados os estímulos do CRQ - Conselho Regional de Química - em preparar palestras a serem ministradas em escolas para estimular os estudantes da Educação Básica a considerarem essa opção profissional. ${ }^{8} \mathrm{Ou}$ ainda as ações do $\mathrm{CNPq}$ - Conselho Nacional de Desenvolvimento Científico e Tecnológico - como o Prêmio José Reis de Divulgação Científica e Tecnológica e a criação de uma página específica sobre popularização da ciência no sítio da internet do próprio órgão. ${ }^{9}$ Outra ação de divulgação científica digna de nota é a atribuição do ano de 2011 como o Ano Internacional da Química. Essa ação da UNESCO (Organização das Nações Unidas para a Educação, a Ciência e a Cultura) e da IUPAC teve o intuito tanto de comemorar os avanços e contribuições para a sociedade obtidos nessa área como também estimular ações que visassem mostrar a Química como algo mais próximo do cotidiano das pessoas e também mais atraente. ${ }^{10}$

É digno de nota que essa imagem que a Química possui para uma parcela da sociedade não é extensível para os termos Ciência e Tecnologia (C\&T). Em 2015, o Ministério da Ciência, Tecnologia e Inovação (MCTI) realizou uma pesquisa de "percepção pública da C\&T". A pesquisa quantitativa contou com a aplicação de um 
questionário de 105 perguntas aplicado a uma amostra da população brasileira com faixa etária a partir de 16 anos. Os idealizadores destacam que levantamentos dessa natureza têm importância acadêmica e política:

Conhecer essa percepção é de grande relevância, tanto no âmbito acadêmico quanto político. Tais informações permitem formular políticas públicas, compreender a aceitação de inovações tecnológicas e aperfeiçoar formas de popularizar e ensinar as ciências. Além disso, ajudam a entender os fatores que levam os jovens a escolher, ou não, carreiras científicas. Fatores que quando compreendidos permitem promover a inclusão social. ${ }^{11}$

A maioria dos respondentes $(60,9 \%)$ definiu-se como interessado ou muito interessado em C\&T e $72,8 \%$ entendem que a $C \& \mathrm{~T}$ trazem apenas benefícios ou mais benefícios que malefícios para a humanidade. Ao mesmo tempo, $87,2 \%$ dos entrevistados não se lembram de alguma instituição que se dedique a fazer pesquisa científica no país e 93,3\% não se lembram do nome de algum cientista brasileiro importante. No que concerne à relação com centros e museus de ciências, $87,6 \%$ não visitou um centro ou museu de C\&T nos 12 meses anteriores. Dado o interesse em C\&T indicado em questões anteriores, é possível sugerir que esse baixo contato com espaços de divulgação científica ocorre pelo baixo número de centros e museus no país.

As iniciativas de se trabalhar a imagem da Química perante a sociedade não são recentes e não se restringem ao âmbito nacional. Em 1990, a Association of Science-Technology Centers (ASTC) promoveu uma conferência em Belmont, nos Estados Unidos da América (EUA), para discutir os resultados de um levantamento sobre a presença da Química em museus de ciências e refletir sobre possíveis novas ações. Em 1993, o European Collaborative for Science, Industry and Technology Exhibitions - ECSITE, a principal associação de Centros e Museus de Ciência europeia, organizou outra conferência com intuito semelhante e criou o projeto "Chemistry in European Museums - ChEM" para desenvolver 50 módulos interativos e inovadores de Química até o ano 2000. Ao final do projeto foram exibidos 30 produtos que abordavam a Química do cotidiano para serem disponibilizados em diferentes museus. ${ }^{12}$

Outra iniciativa nascida nos EUA ocorreu em 2010 em um workshop promovido pela National Research Council com a temática "Química no horário nobre e online: comunicação química em ambientes informais". ${ }^{13}$ O propósito do evento foi levantar a divulgação científica em Química na televisão, na internet, discutir como o público se apropria da informação científica e como químicos podem disseminar o conhecimento que produzem para a população em geral. ${ }^{14}$ Uma ampla gama de diferentes formas de se divulgar a Química de forma acessível foi encontrada tanto na forma de vídeos e jogos como também em alguns museus nos quais a Química está bem caracterizada e presente em seus espaços. Este é o caso dos museus Marion Koshland Museum em Washington (EUA), o Deutsches Museum na Alemanha e o Chemical Heritage Foundation na Filadélfia (EUA)

Esse contexto ilustra a importância de museus e centros de ciências para contribuir com a educação científica ${ }^{15}$ e despertar o interesse das pessoas por $\mathrm{C} \& \mathrm{~T},{ }^{16}$ sendo atualmente bastante valorizado o aspecto interativo do acervo. ${ }^{17}$

Historicamente, o museu tem o papel de relacionar o indivíduo e a sociedade através de suas exposições e bens culturais que dão origem ao patrimônio cultural, resgatando para o visitante, não importando sua tipologia, uma redefinição de sua experiência histórica, cultural e da sociedade..$^{18}$ Esses espaços tornaram-se lugares onde os visitantes têm um encontro com o que foi conquistado pelo ser humano no passado, com a realidade de seu cotidiano e uma perspectiva para o futuro. ${ }^{19}$

Os centros/museus, hoje em dia, aparecem como um espaço de aprendizagem ativa e apresentam uma interface ligada ao público que frequenta. Suas exposições podem ser apresentadas com objetivos variados, como educação, lazer, ambiente de informação e inclusão social, despertando o interesse do público em geral. ${ }^{20} \mathrm{~A}$ exposição é a comunicação do museu com o público e, com base nisso, é importante que todas as etapas sejam planejadas, como a elaboração da exposição, escolha do tema, conceitos que serão trabalhados no museu, elaboração do seu conteúdo, audiovisuais, comunicação e divulgação. ${ }^{21}$

Os museus possibilitam ao público que os visitam desenvolver diversas habilidades que envolve manipulação, motivação ou criatividade. ${ }^{22}$ Suas exposições ajudam a expandir a imaginação e investigação dos objetos expostos, estimulando o entendimento do mundo. ${ }^{23}$

Os aspectos didáticos, informações minuciosas, são indispensáveis para que os museus se tornem uma escola de ensino prático sem que haja professores. ${ }^{24}$

Dessa maneira, a visitação ao museu pode ser considerada uma atividade integradora, reflexiva e também considerada uma complementação da educação escolar. ${ }^{25}$

As exposições museais podem ser classificadas por disciplinas escolares como física, química, biologia, história natural, geografia, etc. Já a interdisciplinaridade aparece em uma abordagem epistemológica e sociológica. ${ }^{26}$

Com o intuito de unir ideias, compartilhar experiências e projetos, trocar informações, identificar, fortalecer, difundir e apoiar programas de divulgação científica entre Centros e Museus de Ciências do Brasil surgiu em 15 de Julho de 1998 a Associação Brasileira de Centros e Museus de Ciências (ABCMC) como representação de todos os Centros e Museus de Ciências do Brasil:

A colaboração entre os diversos museus, centros e grupos pode influir numa política de disseminação do conhecimento científico. Fortalecendo, assim, sua importância para o desenvolvimento do país e contribuindo para uma percepção da ciência em todas as suas dimensões: fonte de prazer, de transformação da qualidade de vida e da relação entre os homens. Identificar, interferir e compreender, criticamente, as possibilidades e os limites do saber científico na nossa história fazem parte da construção da cidadania (ABCMC, 1999, s.p. $)^{27}$

No ano de 2005, como forma de divulgação e consulta dos Centros e Museus de Ciências do Brasil, foi elaborada a primeira catalogação, editada pela ABCMC, pela Casa da Ciência (da Universidade Federal do Rio de Janeiro) e pelo Museu da Vida (Casa de Oswaldo Cruz/ Fiocruz) com apoio do MCTI. A segunda versão foi produzida em 2009 e em 2015 foi lançado o mais recente Guia de Centros e Museus de Ciência do Brasil 2015.28

Na catalogação de 2015 constam 268 centros/museus em todo o Brasil, um aumento de $41 \%$ em relação à versão de 2009 , crescimento este predominante na Região Sudeste. De acordo com o guia, um problema que se enfrenta para fazer a catalogação é devido ao tamanho do território nacional, que dificulta a comunicação e o acesso para determinar o número exato de centros/museus.

No que concerne especificamente à Química, algumas iniciativas de levantar o que há dessa área em museus e centros de ciências e como essas atividades são concebidas e desenvolvidas estão retratadas na literatura. Uma delas ocorreu nos Estados Unidos por iniciativa da ASTC em 1990, cujos resultados estão publicados no livro "A Formula for Success: Chemistry at Science Museums" de Michael 
Templeton. ${ }^{12}$ Um questionário foi enviado para 185 instituições museais com o intuito de determinar a abrangência, o tipo e a quantidade de atividades de Química nesses locais. Das instituições que responderam ao questionário, apenas $32 \%$ afirmaram que mantinham uma exposição na área de Química, sendo que parte significativa dela estava associada à área de Física. Desses resultados, é possível destacar que apesar de a maioria não apresentar uma seção específica de Química, 2/3 dos respondentes afirmaram desenvolver atividades nessa área, como cursos para formação de professores.

Outro estudo utilizou visitas presenciais em museus portugueses, envio de correio eletrônico para os responsáveis por diferentes museus de ciências internacionais e ainda acesso às páginas da internet das instituições que não retornaram contatos anteriores. ${ }^{12} \mathrm{~A}$ autora confirmou sua hipótese prévia de que a Química é escassa em museus de ciências e apontou como principais causas o custo de concepção e de manutenção dos módulos interativos, questões de segurança, a necessidade de monitorização dos visitantes, de gestão de resíduos, a própria natureza dos processos químicos, além de limitações de espaço físico das instituições.

Apesar da reconhecida a contribuição que museus e centros de ciências têm na divulgação e valorização das diversas áreas do conhecimento, na área de Química poucas são as exposições e atividades dedicadas a essa temática. ${ }^{29,30} \mathrm{~A}$ literatura mostra que as dificuldades inerentes à implementação da área de Química em um museu são diferentes e próprias dessa área. Apesar desses reconhecidos entraves, ainda assim são vários os exemplos de atividades e projetos museais envolvendo a Química.

O objetivo deste artigo é realizar um levantamento da Química nos centros/museus brasileiros para se delinear qual o espaço que essa área científica ocupa nesses espaços não formais de Educação.

\section{PARTE EXPERIMENTAL}

A pesquisa aqui descrita caracteriza-se como qualitativa uma vez que predomina o caráter descritivo do cenário da Química em museus buscando-se compreender os motivos que permeiam esse fenômeno. ${ }^{31}$ Nesse tipo de pesquisa, o mais importante não são os dados que aparecem mais frequentemente: todas as informações retiradas do estudo mostram-se com um rico potencial de fornecimento de dados..$^{32} \mathrm{~A}$ amostra recomendada para uma pesquisa qualitativa é de $10 \%$ da população original. ${ }^{33}$

Um questionário de múltipla escolha foi elaborado com perguntas envolvendo a caracterização do museu/centro, se há desenvolvimento de pesquisas na instituição e se existe Química ou não no local. Em caso afirmativo, questionavam-se quais atividades eram desenvolvidas, como foram concebidas e se elas são consideradas interativas. Se o responsável afirmasse que não havia Química no espaço, solicitava-se que comentasse por que não havia, se houve em outro momento, se considera importante e se teria interesse na implementação desse setor.

Os questionários foram enviados em sua versão online para 268 instituições constantes na catalogação mais recente da ABCMC, de 2015. Optou-se por incluir um museu de ciências conhecido, mas que não está na catalogação, talvez por ter sido criado recentemente. $\mathrm{O}$ formulário ficou disponível para ser respondido pelos dirigentes de agosto de 2016 até janeiro de 2017. Nesse período, ele foi reenviado procurando incentivar novas manifestações.

Do total de contatos, 21 centros/museus não possuem contato eletrônico, o que acabou não possibilitando o envio do questionário; 7 retornaram informando que o espaço está fechado para manutenção; 2 esclareceram que se tratam exclusivamente de um museu virtual e 3 recusaram-se a responder por não disponibilizarem um espaço para a Química.
Em continuidade à coleta de dados, procedeu-se ao contato telefônico com os museus/centros de ciências restantes. Foram contatadas 202 instituições, solicitando-se que respondessem o questionário.

Finalmente, utilizou-se como recurso o acesso ao sítio da internet das instituições constantes no catálogo da ABCMC com o intuito de levantar as informações daqueles espaços cujo contato via correio eletrônico ou telefônico não ocorreu com sucesso em semelhança ao procedimento adotado por Pinto. ${ }^{12}$ Em virtude da restrição da coleta aos dados que foram disponibilizados nas páginas dos museus/centros, este meio não contemplou todas as perguntas do questionário elaborado inicialmente. No entanto, foi suficiente para completar o cenário da Química em museus/centros de ciências brasileiros.

\section{RESULTADOS E DISCUSSÃO}

Após os diversos contatos e finalizados os prazos estipulados para os responsáveis pelos museus responderem ao formulário, foram obtidos 80 questionários considerados válidos - 51 a partir dos formulários eletrônicos, 29 por contato telefônico - o que equivale a $30 \%$ do total de centros e museus consultados e encontra-se acima do mínimo necessário para uma amostra qualitativa. ${ }^{33}$

Dos 268 museus catalogados pela ABCMC, 59\% possuem páginas na internet, $28 \%$ não possuem, $10 \%$ são citados em outros endereços eletrônicos (prefeitura e universidade) e 3\% possuem site, mas no momento estão fora do ar. Foi possível observar que dos museus que possuem página de internet, 10 destes não fazem atualizações recentes, sendo 3 com última atualização em 2013, 2 em 2014 e 5 em 2015.

A seguir serão apresentadas e discutidas as informações levantadas junto às instituições museais por contato eletrônico e telefônico. As informações obtidas nas páginas de internet serão incorporadas apenas na discussão para se delinear o espaço da Química nos centros/ museus de ciências brasileiros. A amostra utilizada para discutir o espaço da Química é de 159 museus, o que inclui os contatos eletrônico, telefônico e por sítio eletrônico equivalendo a $59 \%$ do total de instituições catalogadas na ABCMC.

\section{Caracterização geral dos centros e museus}

Com relação aos responsáveis por esses espaços não-formais, $64 \%$ é do sexo masculino e destes $49 \%$ trabalha há até 10 anos nesses espaços. Os diretores de museus com mais de 20 anos de experiência representam $41 \%$ da amostra e $10 \%$ dos respondentes trabalham de 11 a 20 anos nos museus ou centros de ciências.

Das áreas do conhecimento que podem ser encontradas nos centros e museus de ciências brasileiros, incluiu-se também os dados de acesso ao sítio eletrônico. Os 159 museus que possuem páginas de internet são constituídos de diversas áreas relacionadas ou não a Ciências Naturais, sendo elas: Astronomia, Biologia, Física, Geografia, Geologia, Paleontologia, História, Química e Tecnologia. Já a distribuição dessas diferentes áreas nos museus não parece ser homogênea, segundo a descrição constante nos sítios eletrônicos, conforme a Figura 1.

Com relação à área predominante (Figura 2), dos 159 museus que possuem sítio eletrônico, em $28 \%$ das páginas não é possível identificar essa informação. Nas páginas de 38\% dos museus a área predominante é a Biologia, $11 \%$ História e em 9\% a Astronomia. A Geologia aparece como tema mais explorado nos sítios eletrônicos com 5\%, a Arqueologia em 4\%, a Paleontologia em 1\% e a Química é a área predominante apenas no único museu no qual esse tema foi identificado por acesso à página da internet das instituições museais.

Como pode ser observado na Figura 3, a Região Sudeste é a que concentra a maior parte das instituições museais com 155 centros/ museus. É desta região também que foi obtida a maior taxa de retorno 


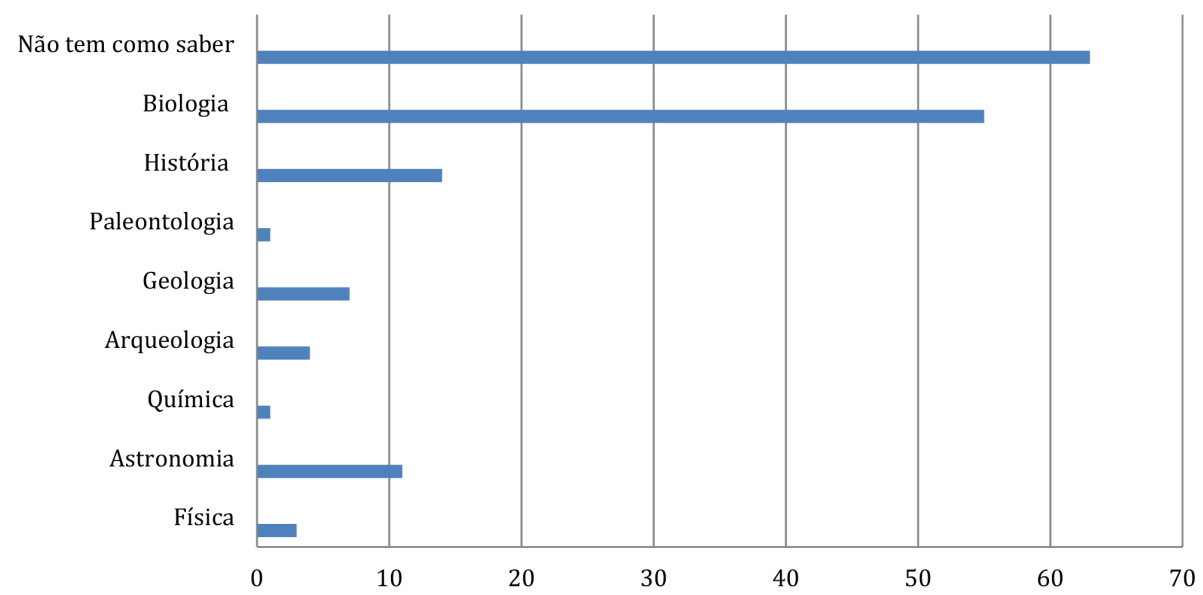

Figura 1. Gráfico da descrição das diferentes áreas do conhecimento nos centros e museus de ciências que possuem sítio eletrônico

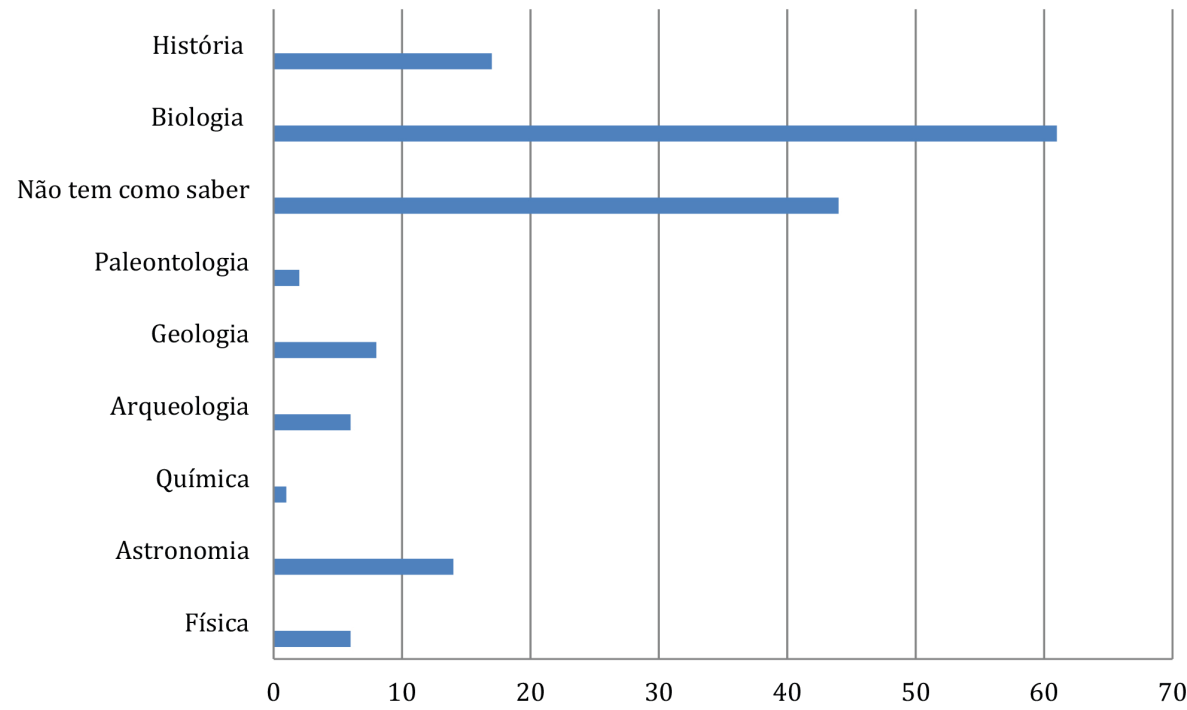

Figura 2. Gráfico da predominância das diferentes áreas do conhecimento nos centros e museus de ciências que possuem sítio eletrônico

dos formulários. A distribuição desses espaços é significativamente menor nas Regiões Nordeste e Sul e bastante tímida nas Regiões Centro-Oeste e Norte. A distribuição geográfica dos centros/museus de ciências no Brasil permite algumas reflexões.

Primeiramente, a Região Sudeste é a que concentra também o maior número de instituições de ensino, especialmente universidades, e que tendem a ser boas opções para parceria para a concepção ou manutenção de espaços de divulgação científica. Além disso, é a região de maior desenvolvimento econômico, científico e tecnológico do país. A presença de maior número de profissionais ligados à Ciência oportuniza o envolvimento de parte deles ou é um fator de pressão de entidades governamentais para que espaços sejam construídos para disseminação da ciência para a população.

O número de centros/museus também acompanha algumas das características próprias de cada região, como extensão territorial. De acordo com o Instituto Brasileiro de Geografia e Estatística (IBGE), ${ }^{34}$ a Região Sul possui aproximadamente $577.000 \mathrm{~km}^{2}$, enquanto que a Região Norte chega a quase 3,9 milhões de $\mathrm{km}^{2}$. Somam-se a isso as dificuldades de acesso em muitas partes, especialmente do norte do país, quando se tornam necessários alguns dias de viagem em diferentes sistemas de transporte para chegar a certas localidades. Há de se ressaltar, no entanto, que apesar de ser a área com o menor número de centros/museus de ciências, muitas ações de divulgação científica são realizadas na Região Norte nas formas de feiras de ciências e mostras culturais. ${ }^{35-37}$ Os relatos das dificuldades empreendidas para levantar recursos e chegar a locais longínquos com dias de viagem e sem infraestrutura de centros/museus de ciências torna a atividade de divulgação científica dependente do comprometimento de estudantes, docentes universitários e poder público. ${ }^{35}$

A interação com a universidade atrai a atenção dos responsáveis pelos museus/centros de ciências (Figura 4). Dos que responderam ao questionário, 55 possuem convênio com universidade, sendo que $27 \%$ é com grupos de extensão, $22 \%$ com pesquisadores, $5 \%$ com grupos de ensino e para $14 \%$ a interação é apenas esporádica.

Daqueles que não mantêm convênio com a universidade (Figura 5), 23\% gostariam de estabelecer interação, 6\% já tiveram e apenas $3 \%$ dos respondentes não percebem necessidade em trabalhar em parceria com universidades.

As diferentes parcerias que podem ser estabelecidas entre universidade e museus de ciências não têm objetivo único de desenvolver o espaço não-formal. Através dessa exposição podem ser criadas ações de formação de recursos humanos, incluindo formação de professores $^{38}$ e graduandos. ${ }^{39}$

Os números relacionados ao envolvimento dos centros e museus com universidades são bastante positivos, já que $68 \%$ desses espaços manifestaram interagir com instituições de ensino superior, mesmo que alguns deles apenas de forma esporádica. Dentro da área da educação em ciências poucos pesquisadores fazem divulgação científica 


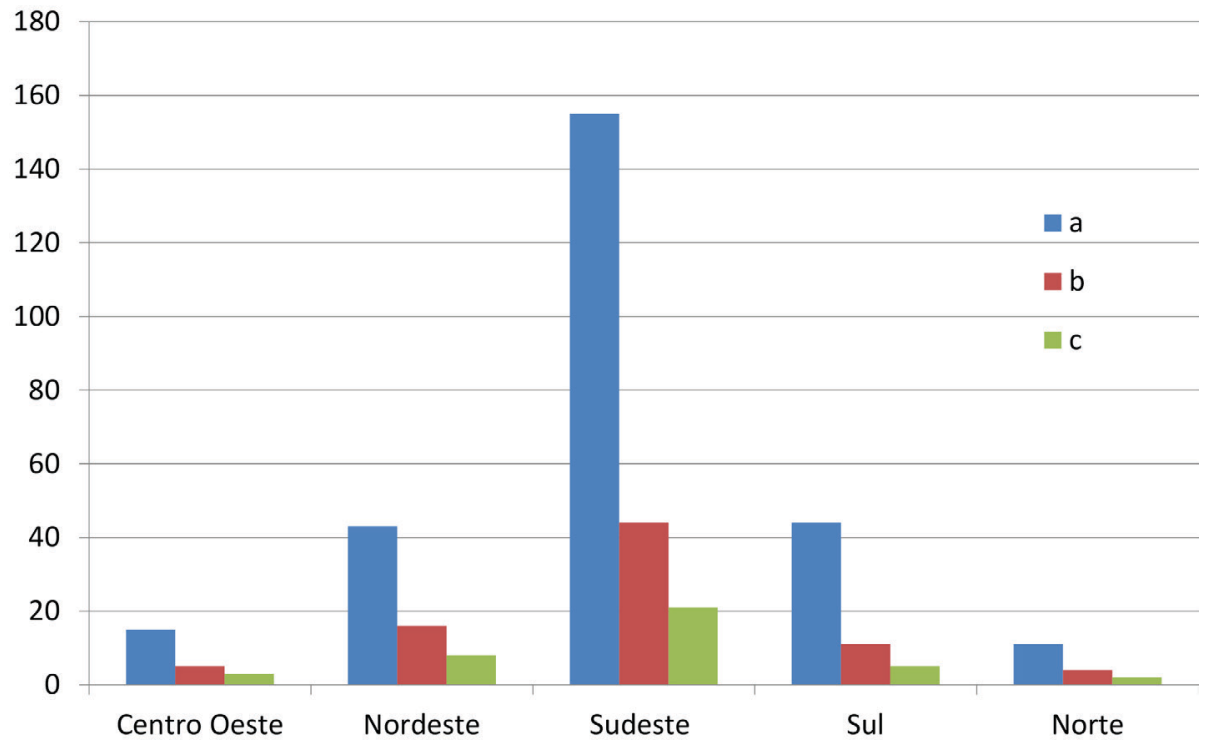

Figura 3. Gráfico comparativo da distribuição geográfica de acordo com o número de centros/museus de ciências no guia da ABCMC (a), do número de respondentes por meio eletrônico, telefônico ou sítio eletrônico (b) e do número de instituições que possuem Química (c)

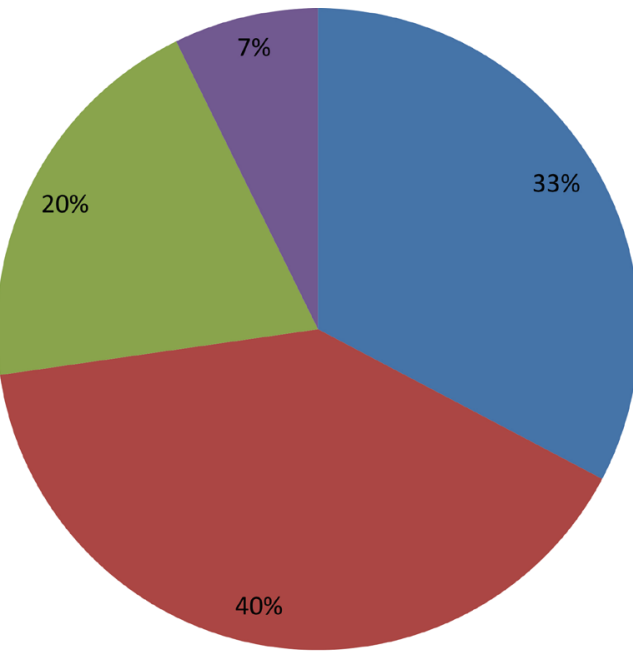

- Sim. Grupos de pesquisa - Sim. Grupos de Extensão - Sim. Esporádica - Sim. Grupos de ensino

Figura 4. Gráfico da relação dos centros e museus de ciências com universidade

em uma das linhas de pesquisa e, com isso, desenvolvem atividades de popularização da ciência ou contribuem com o desenvolvimento de centros e museus de ciências e também publicam artigos em revistas científicas. No entanto, para pesquisadores das outras áreas da Química, atividades de extensão em centros e museus de ciências ou em outras formas de divulgação não se tornam prioridade quando a cobrança por publicação é significativamente maior.

A pressão sofrida por pesquisadores é semelhante em contexto internacional. ${ }^{40,41}$ Jensen $^{40}$ analisou o engajamento com popularização da ciência de 7000 cientistas franceses ao longo de seis anos (2004 - 2009) e verificou que o envolvimento deles aumentou ao longo do tempo. Na área de Química, 46,7\% dos pesquisadores foram considerados ativos nesse sentido. Essa é uma amostra razoável, mas menor do que a porcentagem de ativos nas áreas de Física $(61,3 \%)$ ou Engenharia (55,7\%). Torres-Albero ${ }^{41}$ estudaram o envolvimento de pesquisadores espanhóis com popularização da ciência e verificaram

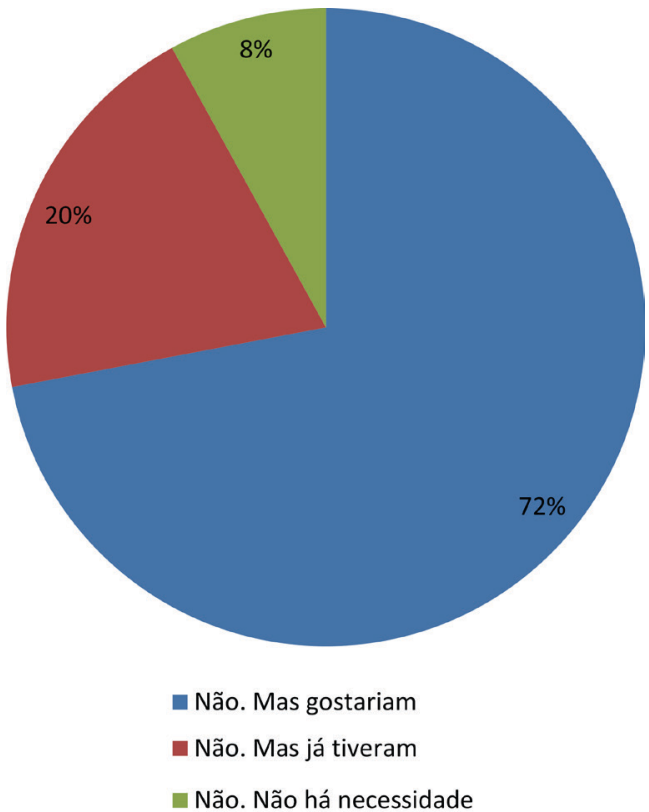

Figura 5. Gráfico da relação dos centros e museus de ciências que não possuem convênio com universidade

que dada a cobrança por publicações específicas, o tempo que resta para a divulgação científica seria o período de descanso do cientista. O envolvimento deles acaba por ser voluntário e com poucos recursos, já que o apoio financeiro institucional é escasso.

Jensen et al. $^{42}$ realizaram ainda outra pesquisa cruzando a proporção de pesquisadores ativos em divulgação científica, a produtividade acadêmica desses cientistas e o reconhecimento institucional de sua atividade em termos de carreiras. Os autores verificaram que os pesquisadores mais ativos em atividades de extensão são os mais produtivos academicamente e que essa dedicação não afeta suas carreiras positiva ou negativamente. Provavelmente, o pesquisador em estágio inicial de carreira tende a ocupar-se mais com a consolidação da mesma, atendendo às pressões para construção de grupo de pesquisa produtivo. Já o cientista com carreira consolidada, na qual esses requisitos já foram logrados, pode voltar seus olhos para compreender e alterar o imaginário que a sociedade possui em relação à ciência. 
Não foi proposta deste trabalho delinear qual o perfil dos pesquisadores universitários com os quais esses centros/museus desta pesquisa relataram estar envolvidos. Assim, não se pode apontar se no contexto brasileiro são os cientistas de carreira consolidada, iniciantes ou ainda aqueles cujas linhas de pesquisa são divulgação científica. Todavia, a contribuição que museus e centros de ciências podem oferecer para melhorar a imagem da Química diante da sociedade e para incentivar que estudantes de ensino médio interessem-se por essa carreira científica mostra que o engajamento dos cientistas com espaços não-formais é necessária e urgente. As organizações científicas e governamentais precisam fomentar esse envolvimento e premiar as boas ações de modo a valorizar quem se dedica a divulgação.

Os responsáveis pelos centros/museus de ciências também foram questionados se são realizadas pesquisas nesses espaços. Semelhantemente à interação com a universidade, os atores envolvidos com espaços não-formais reconhecem a importância de aliar a investigação às exposições e atividades museais. Em $42 \%$ dos respondentes, as pesquisas são realizadas nos próprios museus, enquanto que em $30 \%$ há pesquisas a partir da parceria com universidades. Em $7 \%$ não se desenvolvem pesquisas, apesar de já o terem feito e apenas $3 \%$ não sentem necessidade. Finalmente, $22 \%$ não desenvolvem pesquisa, mas gostariam de fazê-lo.

Pela própria natureza das ações da universidade, pautadas no princípio do ensino-pesquisa-extensão, a aproximação dos pesquisadores dos centros e museus de ciências poderia ocorrer segundo esse mesmo tripé. Ao desenvolver pesquisas nesses espaços, novos conhecimentos poderiam ser produzidos com formação de recursos humanos - tal como são os objetivos das pesquisas acadêmicas - e novas exposições poderiam ser concebidas para enriquecer o acervo dos museus. No entanto, o que se verifica é que grande parte dos trabalhos desenvolvidos pela universidade junto a espaços não-formais ocorre na forma de extensão.

A maior concentração de trabalhos na forma de extensão pode ser exemplificada quando se obtém os dados de trabalhos aceitos no Encontro Nacional de Pesquisa em Educação em Ciências (ENPEC), o evento mais importante na área de Educação em Ciências. Nas últimas três edições do evento - 2011, ${ }^{43} 2013^{44}$ e $2015^{45}$ - foram apresentados 96,57 e 80 trabalhos respectivamente na linha temática "Educação em Espaços não Formais e Divulgação Científica" representando $8 \%, 4 \%$ e $4 \%$ do total de trabalhos das respectivas edições do evento. Já em relação às publicações em revistas científicas os números são significativamente menores. Martinhão e Kasseboehmer ${ }^{46}$ levantaram os artigos científicos publicados em revistas classificadas no sistema Qualis Capes 2014 pela área de avaliação/conhecimento "Ensino", pela classificação "A1" em versão on line. No período de 2005 a 2015, dos 2821 artigos publicados, 13 abordaram a temática museus de ciências. Apenas um abordou sobre a temática museus e Química. Feita a ressalva de que as revistas não eram especializadas na área de divulgação científica e, portanto, naturalmente recebem artigos de diversas naturezas, ainda assim é representativo de como as pesquisas envolvendo museus de ciências ainda estão incipientes.

A seguir será apresentado e discutido o espaço da Química em museus e centros de ciências brasileiros.

\section{O espaço da Química em museus e centros de ciências brasileiros}

No levantamento por contato eletrônico ou telefônico, quando questionados sobre se há Química em seu centro/museu, 38\% responderam afirmativamente. Por se tratar de uma pesquisa qualitativa, esse número não pode ser extrapolado para a realidade brasileira. No entanto, este levantamento por amostragem possibilita especular quais motivos impedem que esse setor possa se desenvolver e quais atividades são possíveis naqueles quando um espaço de Química é criado.

No que concerne à importância que os responsáveis pelos museus atribuem à presença da Química em museus, oito dirigentes (10\%) não reconhecem essa importância. As justificativas apresentadas são que a área não se insere na temática do museu (5\%), 3\% não veem necessidade e $3 \%$ não têm opinião. Dos que entendem que Química é relevante em um centro/museu de ciência, para $31 \%$ deles é para efetivar a interdisciplinaridade; para contextualizar o conhecimento com o cotidiano (26\%); para despertar a curiosidade do visitante (10\%). A importância dessa área pela geração de conhecimento para sociedade foi levantada por $5 \%$, para a divulgação da ciência por $4 \%$ dos dirigentes e como ferramenta pedagógica por $5 \%$ deles. $25 \%$ dos respondentes apontaram que a presença da área é importante sem justificar sua opinião.

Curiosamente, os números correspondentes à existência da Química (38\%) e o número de dirigentes de centros e museus que reconhecem a relevância da mesma (90\%) são discrepantes. Esses dados podem significar que não bastam o interesse ou a vontade dos responsáveis por espaços não formais para que uma ou outra área seja implementada em seus espaços. Além de investimentos das iniciativas pública e privada, que são indispensáveis para que ideias se concretizem, faltam também profissionais habilitados e formados para que esse setor possa ser concebido e idealizado em consonância com o conhecimento desenvolvido por quem pesquisa a divulgação da ciência.

Nos 50 museus que participaram desta pesquisa e não desenvolvem atividades de Química, as justificativas apresentadas para a não existência da área foram que a Química não é objetivo do centro/ museu $(60 \%)$, não possuem pessoal capacitado para desenvolver atividades (14\%), não possuem infraestrutura adequada (14\%) ou faltam recursos financeiros (4\%). Para um responsável (2\%), apenas não houve oportunidade de realizar atividades, para outro (2\%) faltam propostas que sejam possíveis de realizar enquanto que um (2\%) explicou que desenvolvem atividades de Química de forma esporádica e outro (2\%) afirmou que a área ainda está em fase de concepção. A seguir é transcrito o depoimento de um dirigente de museu sobre a (falta da) Química em centros e museus de ciências:

A Química está presente em tudo, o seu ensino é fundamental para o desenvolvimento cognitivo de crianças, jovens $e$ adultos, serve para entender fenômenos químicos, suas tecnologias e aplicações para nossa sociedade, porém dentro dos museus sua manipulação se torna complicada por não termos profissionais capacitados ou alguém que tenha desenvolvido a fórmula de torná-la interativa dentro do museu sem que tenha riscos aos visitantes. Ela deveria ser mais explorada pelos museus de ciência, é uma pena que falte interesse para isso.

Desses espaços, oito indicaram que a Química já foi abordada nesses locais no passado e deixou de ser apresentada pelos seguintes motivos: o acervo deixou de fazer parte do contexto da instituição, as atividades eram apenas pontuais e faltaram pessoal capacitado e recursos financeiros.

As propostas relacionadas à área de Química nesses locais eram experimentos ou "Show da Química" e exposição de objetos. Outros dois explicaram que a área encontrava-se em atividades pontuais, como a temática fotossíntese, ou na produção de réplicas de materiais arqueológicos para as exposições permanentes. Enquanto nos primeiros casos a área estava representada por experimentos, nos outros dois a Química apareceu na intersecção com áreas científicas como Biologia e Paleontologia. Essas áreas são significativamente mais fortes em termos de divulgação cientifica e espaços não-formais 
dadas a facilidade de se encontrar Biologia e áreas afins em museus e centros de ciência. Isso sugere que, provavelmente, a exposição foi concebida por biólogos que consideram explorar também a Química em sua atividade.

Quanto ao interesse em criar um setor de Química, dentre os 50 museus, $60 \%$ responderam negativamente, por entenderem que não existe relação da Química com a proposta do museu, porque a área já está contemplada em outra temática ou ainda por falta de espaço e pessoal capacitado. Ao mesmo tempo, quando questionados se já receberam proposta, apenas $4 \%$ responderam que sim. O índice razoável de interessados em abrigar um setor de Química juntamente com o baixo número de espaços que foram procurados com proposições de atividades vislumbram o potencial que ainda pode ser desenvolvido na área de divulgação científica em Química no Brasil. Faz-se necessário, portanto, que profissionais sejam formados, grupos de pesquisa sejam criados e cursos de especialização sejam oferecidos de modo a capacitar pessoas para trabalhar nessa área.

As dificuldades apontadas pelos responsáveis pelos centros e museus para sediar um setor de Química são em sua maioria semelhante às discriminadas na literatura. ${ }^{12,22,30}$ Chama a atenção, no entanto, a porcentagem significativa de respostas $(60 \%)$ que indicam que não é objetivo do centro/museu abrigar um setor de Química. Ainda que muitos dos espaços constantes no guia da ABCMC sejam Jardins Botânicos ou Zoológicos, qualquer espaço não formal possui potencial para se explorar as diferentes áreas das Ciências Naturais. A manifestação de que o objetivo do espaço é outro pode ser um indicativo de que o local é "fechado" para novas abordagens e parcerias.

Dadas as indicações da literatura de que a área de Química é pouco explorada em museus em todo o mundo, incluiu-se no questionário uma pergunta sobre se os responsáveis pelos centros/museus entendem ser possível trabalhar Química em outros setores de seus espaços. Para 39\% dos dirigentes essa interação não seria possível e $4 \%$ manifestaram não ter opinião a respeito. Dos que vislumbram a possibilidade de abordar Química em outros setores, apenas 4\% fizeram uma proposta, e que seria a conservação de materiais. Das manifestações restantes, $32 \%$ explicaram não saber como se poderia trabalhar e 7\% que dependiam de iniciativa. Outros 14\% responderam afirmativamente, mas sem justificar-se.

Todos os responsáveis pelos centros/museus foram convidados a relatar sobre a dificuldade em manter ou criar um setor de Química (Figura 6). Dos respondentes, 39\% afirmaram que a área não se encaixa na temática do museu, confirmando as indicações anteriores de que esses espaços não reconhecem a necessidade de um setor de Química nem de desenvolver essa área de forma interdisciplinar. Das respostas restantes, foi possível verificar que a maior dificuldade em manter um setor de Química é a falta de recursos financeiros (26\%), seguido da necessidade de manutenção de materiais e reagentes (10\%) e infraestrutura (10\%) e riscos de acidentes com produtos químicos (5\%). Para três respondentes (4\%) faltam ideias de atividades propícias ao museu, para outros $4 \%$ não há interesse dos responsáveis e, para $2 \%$, faltam monitores.

Os motivos apresentados pelos participantes desta pesquisa são semelhantes aos relatados na literatura. ${ }^{12}$ A caracterização da área de Química como sendo predominantemente experimental remete à ideia de que trabalhá-la em atividades de divulgação científica necessariamente envolve a manipulação de produtos químicos. Mesmo que esses produtos sejam retirados do cotidiano da população de modo a contribuir para a aproximação com a realidade dos visitantes, produtos comerciais não podem ficar expostos sem supervisão de um responsável da própria instituição. A criação de um setor de Química em um centro ou museu de ciência depende, portanto, do desenvolvimento de ideias inovadoras que possibilitem representar uma transformação química e o envolvimento do visitante, mas sem

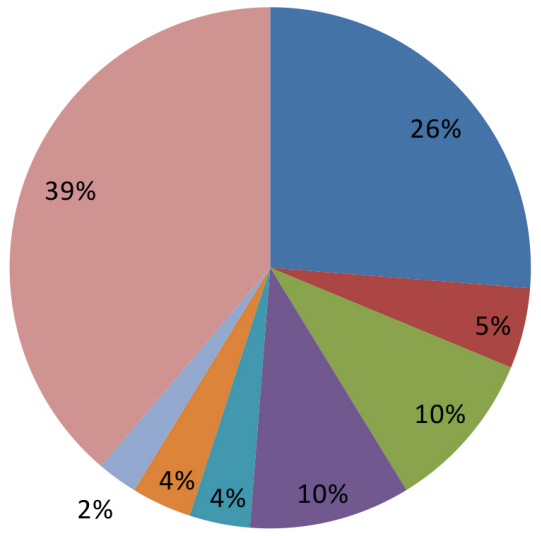

Falta de recursos financeiros

Riscos com acidentes químicos

Manutenção de matérias e reagente

Falta de infraestrutura

Falta de ideias de atividades de Química propicias para museu

Desinteresse dos responsaveis

Falta de monitores

Não se encaixa na temática do museu

Figura 6. Dificuldades de manter ou construir um setor de Química

a exposição direta dele com os reagentes.

Para ilustrar algumas iniciativas publicadas em revistas científicas para compartilhar atividades de Química desenvolvidas para museus de ciências, tem-se o trabalho de Brown et al., ${ }^{47}$ que criaram uma exposição com modelos moleculares para explicar à população geral o conceito de estrutura molecular a partir da relação entre estrutura química e aroma de produtos comerciais. Sheridan et al. ${ }^{48}$ descrevem um programa voltado para aumentar o interesse de estudantes de ensino médio por química e um tipo de acampamento é criado no qual são desenvolvidas atividades nos temas de cristalização, quimiluminescência, cromatografia e diferenças entre substâncias polares e não polares. Os autores explicam que a sistemática pode ser transferida para diferentes locais e envolve alunos de graduação e de ensino médio. Ainda, Silberman, Trautmann e Merkel $^{29}$ descrevem uma sequência de dez atividades criadas para um museu de ciência de Nova Iorque na qual os participantes devem estudar propriedades químicas para resolver alguns enigmas.

Dentre os 30 museus em que há Química, 10 deles (33\%) desenvolvem mais de uma atividade. Predominantemente, a área é contemplada nos centros e museus de ciências pesquisados com a utilização de laboratório para apresentações $(67 \%)$ ou cursos $(40 \%)$ para alunos e professores, tais como monitoria de Química (70\%), oficinas com escolas (70\%), atividades com professores 15 museus (11\%), "Show da Química" (7\%), gincanas ou olimpíadas (7\%) ou ainda a realização de experimentos isolados com o público (3\%).

As exposições que não dependeriam diretamente de monitores ou professores para executarem e que poderiam ser exploradas por um público não específico são encontradas em 24 centros/museus, sendo em 16 deles (53\%) na forma de exposições itinerantes; maquetes interativas (47\%), exposições de materiais antigos/obsoletos $(17 \%)$, materiais interativos na página da internet da instituição do museu $(17 \%)$ ou ainda relacionada a outra área do conhecimento como Geologia (7\%), Biologia (3\%) ou materiais diversos do museu (3\%). A Figura 7 representa a distribuição dos tipos de atividades trabalhadas nos centros/museus participantes da pesquisa. 


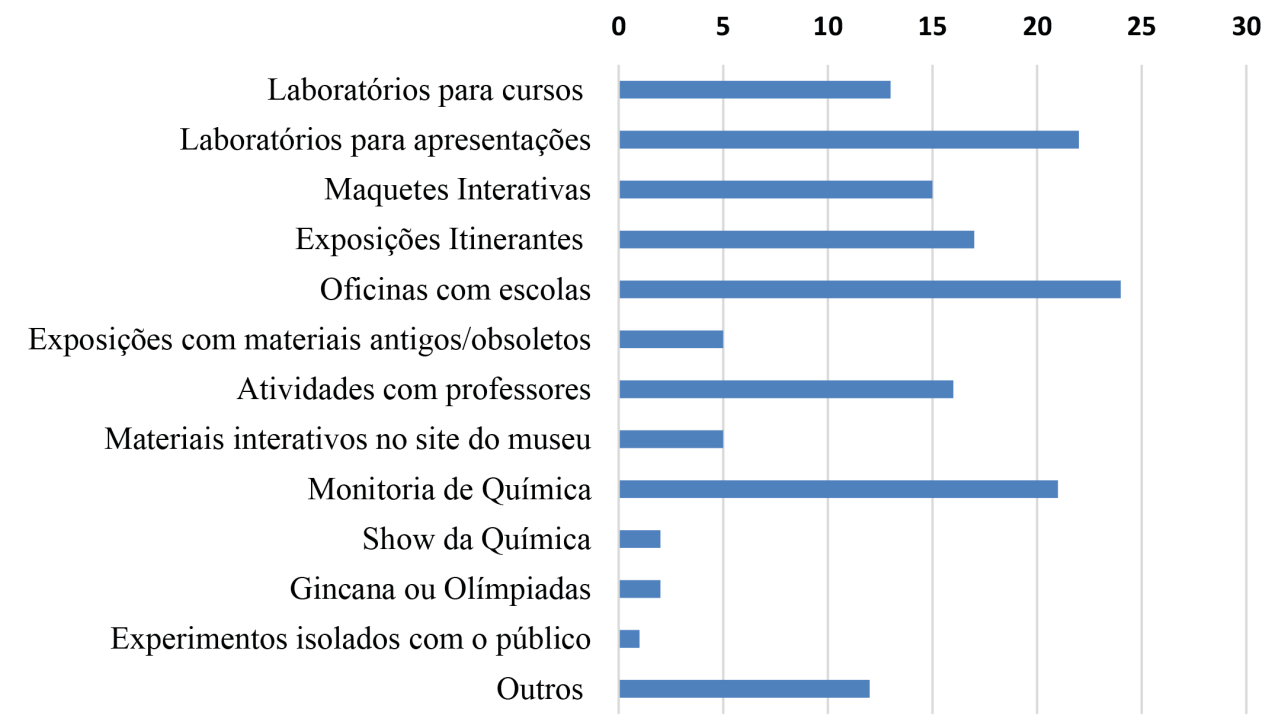

Figura 7. Gráfico da distribuição dos tipos de atividades trabalhadas nos centros/museus participantes da pesquisa

Das atividades desenvolvidas com professores (Figura 8) dentro dos museus, 11 museus especificaram quais são as atividades realizadas sendo, minicursos desenvolvidos pela graduação (27\%), produção de material didático em Química $(27 \%)$, práticas para serem aplicadas em laboratório (18\%), oficinas multidisciplinares (18\%) e formação continuada (10\%). Como temáticas dos minicursos desenvolvidos pela graduação, os responsáveis destacaram que são ligadas ao cotidiano ou que podem envolver outras áreas dos museus: "Química do dia a dia”, "Química na cozinha”, "Os processos Químicos no cotidiano", "Química uma questão ambiental”, "A Química no espaço". O Centro de Ciências da Universidade Federal de Juiz de Fora produz kits com materiais práticos para serem aplicados em sala de aula, oferecendo cursos de formação para professores para sua utilização. Eles desenvolvem também atividades para alunos com deficiência visual, como o uso de tabela periódica adaptada, e para alunos com deficiência auditiva. Esses projetos se iniciaram após o contato de uma aluna com deficiência auditiva que participou da exposição Cadê a Química? e sentiu-se incluída pela qualidade das atividades.

Como forma de complementar o cenário do espaço atribuído à Química em centros e museus de ciências brasileiros, os sítios eletrônicos das 159 instituições que possuem páginas de internet foram acessados. Destes, a área de Química foi mencionada em
$24 \%$, sendo que no restante dos endereços eletrônicos a Química não estava listada entre as áreas contempladas no espaço ou não foi possível identificá-la.

Os dados das páginas de internet das instituições exibem resultados parecidos com o levantamento realizado por meio eletrônico ou telefônico e reforçam que a Química em espaços não formais de Educação ainda é singela. As informações das páginas eletrônicas não foram suficientes para categorizar quais atividades são desenvolvidas nesses locais à semelhança do que foi proposto a partir das respostas dos dirigentes. Daquilo que foi possível obter na leitura da descrição dos objetivos das instituições, muitas instituições centram-se no oferecimento de cursos para alunos e professores da educação básica incluindo o empréstimo de kits para a realização de experimentos nas escolas. Destaca-se aqui a parceria estabelecida entre a Casa de Ciência e Cultura de Campo Grande da Universidade Federal de Mato Grosso do Sul com a Universidade de São Paulo para a implementação da Experimentoteca desenvolvida por esta última para o empréstimo de kits de experimentos para escolas.

A Química também se faz presente na forma de exposições e, neste caso, algumas opções aparecem sem que seja feito uso de materiais e reagentes químicos. Este é o caso do Parque da Ciência vinculado à Secretaria de Estado da Educação do Paraná e localizado

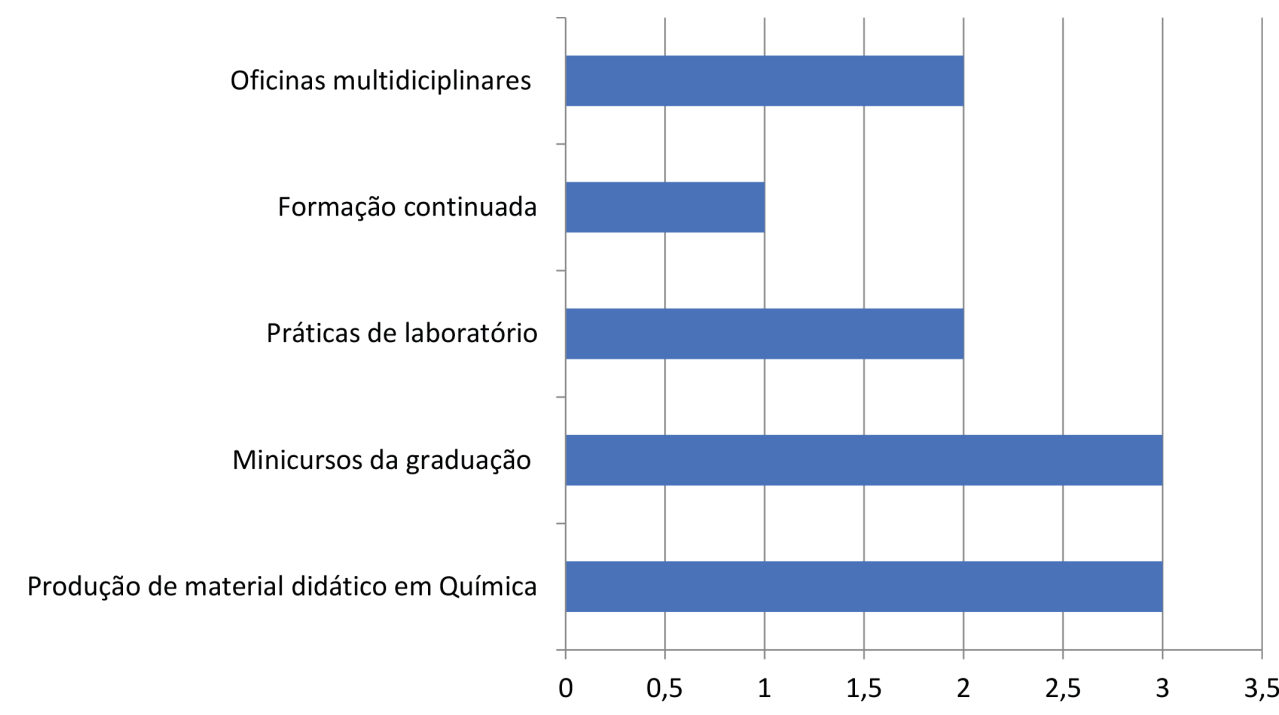

Figura 8. Gráfico da distribuição dos tipos de atividades trabalhadas com professores nos centros/museus participantes da pesquisa 
em Pinhais / PR, que oferece uma exposição com fotos e artefatos que remetem à Alquimia (Figura 9).

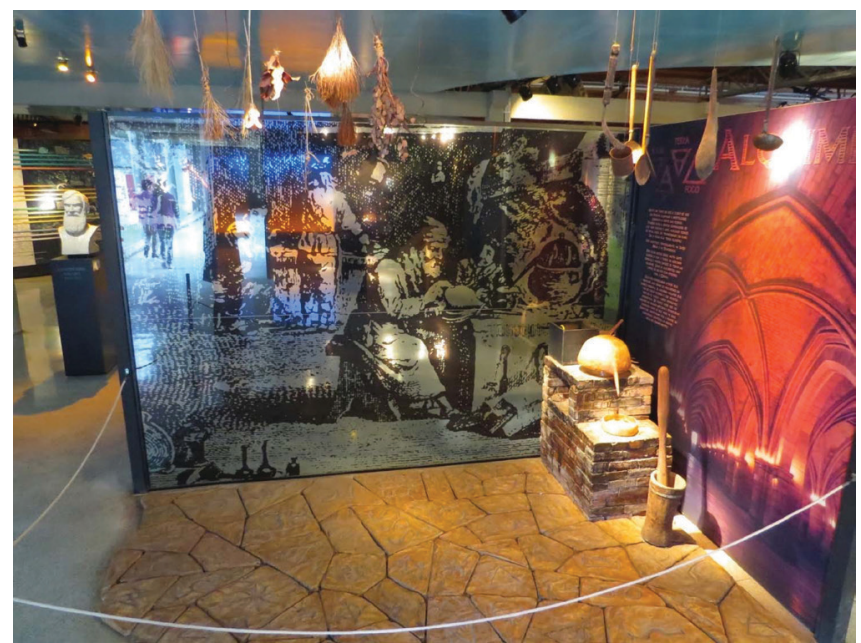

Figura 9. Captura de tela de uma exposição de Química representando a Alquimia no Parque da Ciência / Paraná. Disponível em http://www. parquedaciencia.pr.gov.br/galeria/11/542/Alquimia.html. Acesso em: 04 de maio de 2017

Ainda para exemplificar a presença da área sem a exposição de reagentes ou a necessidade de pessoal permanente para lidar com o público, encontrou-se no sítio do Centro de Ciências da Universidade Federal de Juiz de Fora uma tabela periódica interativa (Figura 10). Com o auxílio de um monitor de televisão, o visitante pode interagir e conhecer algumas das propriedades dos elementos químicos.

Segundo Jacobucci, ${ }^{49}$ não existe um levantamento do número de professores que visitam os museus, o motivo que frequentam esses espaços e como contribuem para sua formação, sendo que a literatura na área de formação de professores em espaços não formais é muito escassa no país.

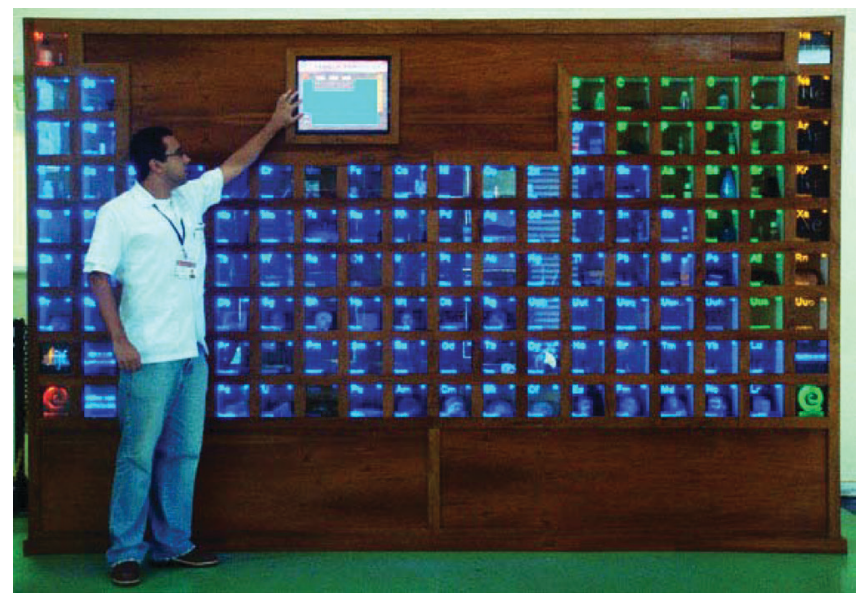

Figura 10. Captura de tela de uma tabela periódica interativa no Centro de Ciências / Minas Gerais. Disponível em http://www.ufjf.br/centrodeciencias/ projetos/tabela-periodica/. Acesso em: 04 de maio de 2017

Os responsáveis pelos centros/museus de ciências também foram questionados sobre quem produz/produziu as atividades de Química. A maior parte das respostas (50\%) refere-se a convênio com as universidades. Em $33 \%$ dos espaços, são elaboradas pelos próprios responsáveis ou mediadores, em outros $13 \%$ por convênio com empresas e em apenas $4 \%$ dos museus quem criou as atividades de Química foram estagiários. A porcentagem significativa de acervo cuja responsabilidade de concepção ocorreu em parceria com universidades remete novamente à importância das instituições de ensino superior para o crescimento e fortalecimentos dos espaços não formais. Entende-se assim que, na medida em que professores universitários forem incentivados a envolverem-se com atividades de divulgação científica e ao mesmo tempo reconhecerem a importância da extensão entre suas atribuições funcionais, os centros e museus de ciências também se beneficiarão.

Finalmente, no que concerne à questão da interatividade nos setores de Química, 63\% dos dirigentes consideram as atividades dessa área interativas apresentando como justificativas a participação dos visitantes e a realização de experimentos na forma de "Show da Química" ou com escolas. Aqueles que afirmaram que não existe interatividade nessa seção do centro/museu explicaram que os experimentos são mediados por monitores, não existindo possibilidade de manipulação dos materiais pelos visitantes ou porque o setor contém apenas exposições permanentes.

É interessante notar que a realização de experimentos por monitores permitiu que alguns dirigentes caracterizassem seu centro/ museu como interativo, o que não ocorreu com outros respondentes. Como explica Colinvaux, ${ }^{17}$ a interatividade pode ser atribuída tanto aos espaços que oferecem experiências hands on quanto aqueles que propõem atividades minds on. No entanto, o autor explica que interatividade não se restringe ao relacionamento entre sujeitos por meio da linguagem, o que é amplamente explorado atualmente. A interação requer também o envolvimento do sujeito com objetos e, ainda, entre sujeitos e contextos, que permita que o visitante desenvolva: "sua capacidade de agir, interrogar e experimentar, como processos cognitivos de interação com o mundo dos objetos, e os contextos museais específicos que convidam, propõem, mas também delimitam as possibilidades de ação, interrogação e experimentação de cada visitante" 17

Para que um setor de Química possa ser considerado interativo, ele não pode ser reduzido à mera manipulação de equipamentos ou experimentos, seja com a mediação ou não de monitores. Os diferentes responsáveis pelos espaços não formais podem ter apresentado diferentes interpretações sobre a interatividade de um mesmo tipo de atividade que é a realização de experimentos. Ainda assim o índice de setores que foram considerados interativos mostra um desenvolvimento satisfatório da Química nos museus.

Em cenário internacional, é possível encontrar museus de ciências europeus que foram construídos antes das primeiras universidades brasileiras. Como importantes contribuições, especialmente do início da Química, são atribuídas a cientistas europeus, muitos países procuraram preservar essa memória em seus espaços não formais. Este é o caso da seção de Química do South Kensington Museum, localizado em Londres/Inglaterra, constituída de materiais antigos, tais como caderno de notas e aparatos de cientistas como John Dalton ou Michael Faraday. ${ }^{50} \mathrm{Ou}$ ainda o Museum of the Leningrad University em São Petersburgo / Rússia criado em homenagem ao químico russo Dmitri Mendeleiev. ${ }^{51}$ Próprio da função atribuída a centros e museus de ciências no início do século XX, esses museus guardam arquivos históricos que auxiliam a recriar parte da história da Química. Todavia, ainda em artigos da mesma época, foi possível encontrar a preocupação dos responsáveis pelos museus e centros de ciências em criar atividades interativas e de divulgação da Química. Sachtleben, ${ }^{52}$ ao descrever a seção de Química no Deutsches Museum em Munique / Alemanha, explica que:

tem sido uma característica do Deutsches Museum que o visitante tenha ampla oportunidade de apertar botões e definir modelos. Na reconstrução da seção de química, foi feito um 
esforço para estender essa tradição a processos químicos. Por exemplo, agora é possível pressionar um botão para reunir quaisquer dois líquidos desejados. ${ }^{53}$

\section{CONCLUSÃO}

Neste artigo é apresentado um levantamento realizado junto a centros e museus de ciências brasileiros para se delinear o espaço da Química em locais não formais de Educação. Informações adicionais relacionadas aos tipos de atividades e envolvimento dessas instituições com universidades e pesquisa foram recolhidas de modo a se construir um cenário da Química em museus.

Os resultados obtidos são semelhantes a alguns dados internacionais que mostram que a Química é escassa em centros e museus de ciências, não ultrapassando o índice de $40 \%$. A maior parte das atividades é voltada para apoio à educação formal com o oferecimento de cursos para professores e estudantes com a utilização de laboratórios ou a realização de experimentos quando há monitor disponível. Poucos foram os exemplos de exposições criadas para que o público geral possa interagir e aprender sobre a área sem a supervisão de um monitor, como pode ocorrer em outras áreas do conhecimento. As dificuldades apontadas para criar ou manter um setor de Química são principalmente financeiras e de recursos humanos.

Ainda assim, são encontrados exemplos em museus brasileiros ou em publicações internacionais de setores e atividades voltadas para a Química, apontando que, apesar de mais trabalhoso que em outras áreas, é possível construir um espaço voltado à divulgação da Química em centros e museus de ciências. Como ocorre/ocorreu na concepção da maioria das exposições hoje encontradas em museus de ciências, a Química pode ser contemplada nesses espaços especialmente em parceria com cientistas que são os sujeitos mais habilitados para abordar a importância da Química sem criar visões distorcidas, sensacionalismos ou equívocos conceituais. Todavia, a pressão que pesquisadores universitários vivem por publicar artigos em revistas especializadas pouco contribui para que eles voltem seus olhares para a popularização dessa ciência.

Para além de meramente criar um setor de Química, esse desenvolvimento necessita ocorrer com intencionalidade, de modo que as atividades apresentadas, inseridas em um contexto elaborado previamente, possibilitem que o visitante vivencie a experiência de conhecer e relacionar-se com o mundo da Química. Desse modo, os centros e museus de ciências poderão cumprir seu papel de motivar e estimular que a população possa reconhecer a importância da Química e compreender o que de fato é essa ciência, seus limites e conquistas.

Nos EUA e Europa, várias das reuniões para se levantar a Química e criar soluções ocorrem por força das associações acadêmicas. Esse pode ser um exemplo a ser abraçado pela comunidade química brasileira. Dados os índices baixos de centros e museus que possuem Química e também a imagem preocupante que a sociedade constrói em relação a essa área, o envolvimento dos pesquisadores universitários dos Institutos e Departamentos de Química torna-se mais urgente.

Como pontuaram autores que relacionaram a dedicação à divulgação científica e o desenvolvimento da carreira científica, cuidar da imagem que a Química possui perante a sociedade não afeta a carreira do pesquisador nem positiva nem negativamente. Porém, esse trabalho repercutirá na própria continuidade da área de Química, incentivando que mais indivíduos interessem-se por estudá-la e desenvolvê-la e reconhecendo-a como um setor importante da sociedade.

\section{AGRADECIMENTOS}

Agradecemos os responsáveis pelos museus e centros de ciências que participaram da pesquisa. Processo n. 2014/02522-7, Fundação de Amparo à Pesquisa do Estado de São Paulo (FAPESP). Processo n. 457780/2013-4, Conselho Nacional de Desenvolvimento Científico e Tecnológico (CNPq).

\section{REFERÊNCIAS}

1. Santos, W. L. P.; ComCiência 2011, 130, 0.

2. Lago, R.; Souza, A. L. A. B.; Purceno, A.; Gontijo, F.; J. Braz. Chem. Soc. 2013, 12, 1889.

3. http://vestibular.unesp.br/pdf/2017/candvaga_19_10_2016.pdf, acessada em Maio 2018.

4. https://www.comvest.unicamp.br/estatisticas/2017/2017_cv_fase1.pdf, acessada em Maio 2018.

5. Zucco, C.; Quim. Nova 2007, 30, 1429.

6. Pérez, G. D.; Montoro, I. F.; Alís, J. C.; Cachapuz, A.; Praia, J.; Ciência \& Educação 2001, 7, 125.

7. http://agencia.fapesp.br/14410, acessada em Maio 2018.

8. http://www.crq4.org.br/programa_palestras_quimica_2013, acessada em Maio 2018.

9. http://www.cnpq.br/web/guest/popularizacao-da ciencia;jsessionid=C8 DADF67A2145E774776667B22374A04http, acessada em Maio 2018.

10. Marson, G. A.; Teruya, L. C.; Rezende, C. M.; Viana, M. H.; Quim. Nova 2013, 36, 1561.

11. http://percepcaocti.cgee.org.br/o-estudo/\#, acessada em Maio 2018.

12. Pinto, V. M. M.; Dissertação de Mestrado, Universidade do Porto, Portugal, 2007.

13. "Chemistry in Primetime and Online: Communicating Chemistry in Informal Environments", tradução nossa.

14. https://www.ncbi.nlm.nih.gov/books/NBK91477/, acessada em Maio 2018.

15. Gruzman, C.; Siqueira, V. H. F.; Revista Electrónica de Enseñanza de las Ciencias 2007, 6, 402 .

16. Falk, J. H., Needham, M. D.; J. Res. Sci. Teach. (2011), doi:10.1002/ tea.20394.2010.11.23

17. Colinvaux, D.; História, Ciência, Saúde 2005, 12, 79.

18. Loureiro, J. M. M.; Ci. Inf. 2003, 32, 88.

19. Gaspar, A.; Tese de Doutorado, Universidade de São Paulo, Brasil, 1993.

20. Chelini, M. J. E.; Lopes, S. G. B. C.; Anais do Museu Paulista 2008, 16, 205.

21. http://www.museus.gov.br/wp-content/uploads/2013/12/Museus_e_ Turismo.pdf, acessada em Maio 2018.

22. Souza, R. F.; Monografia de Especialização, Universidade Tecnológica Federal do Paraná, Brasil, 2014.

23. Carvalho, C.; Lopes, T.; Educação \& Realidade 2016, 41, 911.

24. Lopes, M. M.; O Brasil Descobre a Pesquisa Científica: os museus e as ciências naturais do século XIX, $2^{\text {th }}$ ed., Hucitec: São Paulo, 1997.

25. Cruz, M. P.; Dissertação de Mestrado, Instituto Federal de Educação, Ciência e Tecnologia do Rio de Janeiro, Brasil, 2010.

26. Pinheiro, L.V. R.; Revista Museologia e Patrimônio 2008, 1, 9.

27. http://www.abcmc.org.br/publique1/cgi/cgilua.exe/sys/start.htm?sid=14, acessada em Maio 2018.

28. http://www.abcmc.org.br/publique1/cgi/cgilua.exe/sys/start. htm?infoid=1740\&sid=10, acessada em Maio 2018 .

29. Siberman, R. G.; Traumann, C.; Merkel, S. M.; J. Chem. Educ. 2004, 81,51 .

30. Domenici, V.; J. Chem. Educ. 2008, 85, 1365.

31. Oppenheim, A. N.; Questionnaire Design, Interviewing and Attitude Measurement, Londres e Nova Iorque: Continuum, 2001.

32. Bogdan, R. C.; Biklen, S. K.; Qualitative Research for Education, Boston: Allyn and Bacon, 1982.

33. Fraser, M. T. D.; Gondin, S. M. G.; Paidéia 2004, 14, 139.

34. http://www.ibge.gov.br/home/geociencias/areaterritorial/principal.shtm, acessada em Maio 2018. 
35. Silva, M. I.A.; Santana, E. B.; Valente, J. A S.; X Encontro Nacional de Pesquisa em Educação em Ciências, Águas de Lindóia, Brasil, 2015.

36. Carvalho, R. J.; Silva, F. H. A.; Carmo, C. C.; X Encontro Nacional de Pesquisa em Educação em Ciências, Águas de Lindóia, Brasil, 2015.

37. Deus,V, C.; Oliveira, J. C. C.; Silva, A. A.; Santos, E. S.; Oliveira, A. C.; $X$ Encontro Nacional de Pesquisa em Educação em Ciências, Águas de Lindóia, Brasil, 2015.

38. Monteiro, B. P. A.; Janerine, A. S.; Carvalho, F. C.; Cultural Studies of Science Education 2016, 11, 419

39. Payne A. C.; Prophetis, W. A.; Ellis, A. B.; J. Chem. Educ. 2005, 82, 743.

40. Jensen, P.; Public Understanding of Science 2011, 20, 26.

41. Torres-Albero, C.; Fernandez-Esquinas, M.; Rey-Rocha, J.; MartinSempere, M.; Public Understanding of Science 2011, 20, 12.

42. Jensen, P.; Rouquier, J. B.; Kreimer, P.; Croissant,Y.; Science and Public Policy 2008, 35, 527 .

43. http://abrapecnet.org.br/atas_enpec/viiienpec/index.htm, acessada em Maio 2018
44. http://abrapecnet.org.br/atas_enpec/ixenpec/atas/index.htm, acessada em Maio 2018.

45. http://www.abrapecnet.org.br/enpec/x-enpec/anais2015/index.htm, acessada Maio 2018

46. Martinhão, R. F.; Kasseboehmer, A. C.; Encontro Nacional de Ensino de Química, Florianópolis, Brasil, 2006.

47. Brown, M. K.; Brown, L. C.; J. Chem. Educ. 2017, 94, 251.

48. Sheridan, K. M.; Szczepankiewicz, S. H.; Mekelburg, C. R.; Schiwabel, K. M.; J. Chem. Educ. 2011, 88, 876.

49. Jacobucci, D. F. C.; Jacobucci, G. B.; Neto, J. M.; Revista Electrónica de Enseñanza de las Ciencias 2009, 8, 118.

50. Greenaway, F.; J. Chem. Educ. 1958, 35, 300.

51. Krotikov, V. A.; J. Chem. Educ. 1960, 37, 625

52. Sachteben, R.; J. Chem. Educ. 1957, 34, 283.

53. Sachteben, R.; J. Chem. Educ. 1957, p. 284. 